\title{
At the Cutting Edge
}

Nevro

endocrinology
Neuroendocrinology 2019;109:51-56

DOI: $10.1159 / 000495184$
Received: October 28, 2018

Accepted after revision: November 7, 2018

Published online: November 7, 2018

\section{Giant Prolactinomas}

\author{
Ilan Shimon \\ Institute of Endocrinology, Rabin Medical Center - Beilinson Hospital, Petach Tikva, Israel; \\ Sackler Faculty of Medicine, Tel Aviv University, Tel Aviv, Israel
}

\section{Keywords}

Cabergoline - Dopamine agonist - Giant prolactinoma ·

Prolactin · Prolactinoma

\begin{abstract}
Prolactin-secreting adenomas (prolactinomas) are the most common secreting adenomas of the pituitary. Microprolactinomas (diameter $<10 \mathrm{~mm}$ ) are frequently diagnosed in women, whereas macroprolactinomas (maximum diameter $\geq 10 \mathrm{~mm}$ ) are generally seen in men. Most macroprolactinomas measure between 10 and $40 \mathrm{~mm}$. Giant prolactinomas, measuring $>40 \mathrm{~mm}$, are rare, accounting for only $1-5 \%$ of all prolactinomas. Although generally benign, giant prolactinomas are aggressive and invasive, extending into the suprasellar region and also involving the cavernous sinuses. The optic chiasm is frequently involved, which leads to visual damage, and patients occasionally suffer from ophthalmoplegia. Long-term (usually lifetime) therapy with high-dose dopamine agonists (cabergoline or bromocriptine), together with pituitary surgery in some cases and radiotherapy if required, can achieve biochemical remission, tumor control, and clinical improvement in most patients.
\end{abstract}

(c) 2018 S. Karger AG, Basel

\section{KARGER}

(c) 2018 S. Karger AG, Basel

E-Mail karger@karger.com

www.karger.com/nen

\section{Introduction}

Prolactinomas are the most common hormonally active pituitary tumors ( $\sim 40 \%$ of all pituitary adenomas) with a prevalence of $\sim 5$ per 10,000 population according to epidemiological surveys [1]. They are classified on the basis of size as microprolactinomas $(<10 \mathrm{~mm}$ diameter $)$ and macroprolactinomas ( $\geq 10 \mathrm{~mm}$ diameter). Microprolactinomas are usually seen in women, whereas macroprolactinomas have a male predominance $[2,3]$. The majority of macroprolactinomas measure 10-40 mm. Tumors measuring $>40 \mathrm{~mm}$, termed giant prolactinomas, are rarer, accounting for only $1-5 \%$ of all prolactinomas $[4,5]$. Giant prolactinomas are usually diagnosed in the 20 - to 50-year age group (median 42) in men [4] and occasionally in older or postmenopausal women [6], with a reported male-to-female ratio of $\sim 9: 1$ [5]. Patients present with prolactin levels above $1,000 \mathrm{ng} / \mathrm{mL}(21,000$ $\mathrm{mU} / \mathrm{L}$ ), and usually up to $100,000 \mathrm{ng} / \mathrm{mL}$. Most have hypogonadism associated with low testosterone levels, and some have at least partial hypopituitarism. Most giant prolactinomas are invasive, with suprasellar extension leading to chiasmal compression and involvement of the ventricular system, and parasellar extension into the cavernous sinus and rarely to the temporal lobe (Fig. 1). They may also extend inferiorly into the sphenoid sinus and

\footnotetext{
Ilan Shimon, MD

Institute of Endocrinology, Rabin Medical Center - Beilinson Hospital 39 Jabotinsky Street Petach Tikva 4941492 (Israel)

E-Mail ilanshi@ clalit.org.il
} 
Fig. 1. Coronal MRI T1-weighted sequence, gadolinium enhanced, of two patients with giant prolactinomas at presentation and following cabergoline treatment.

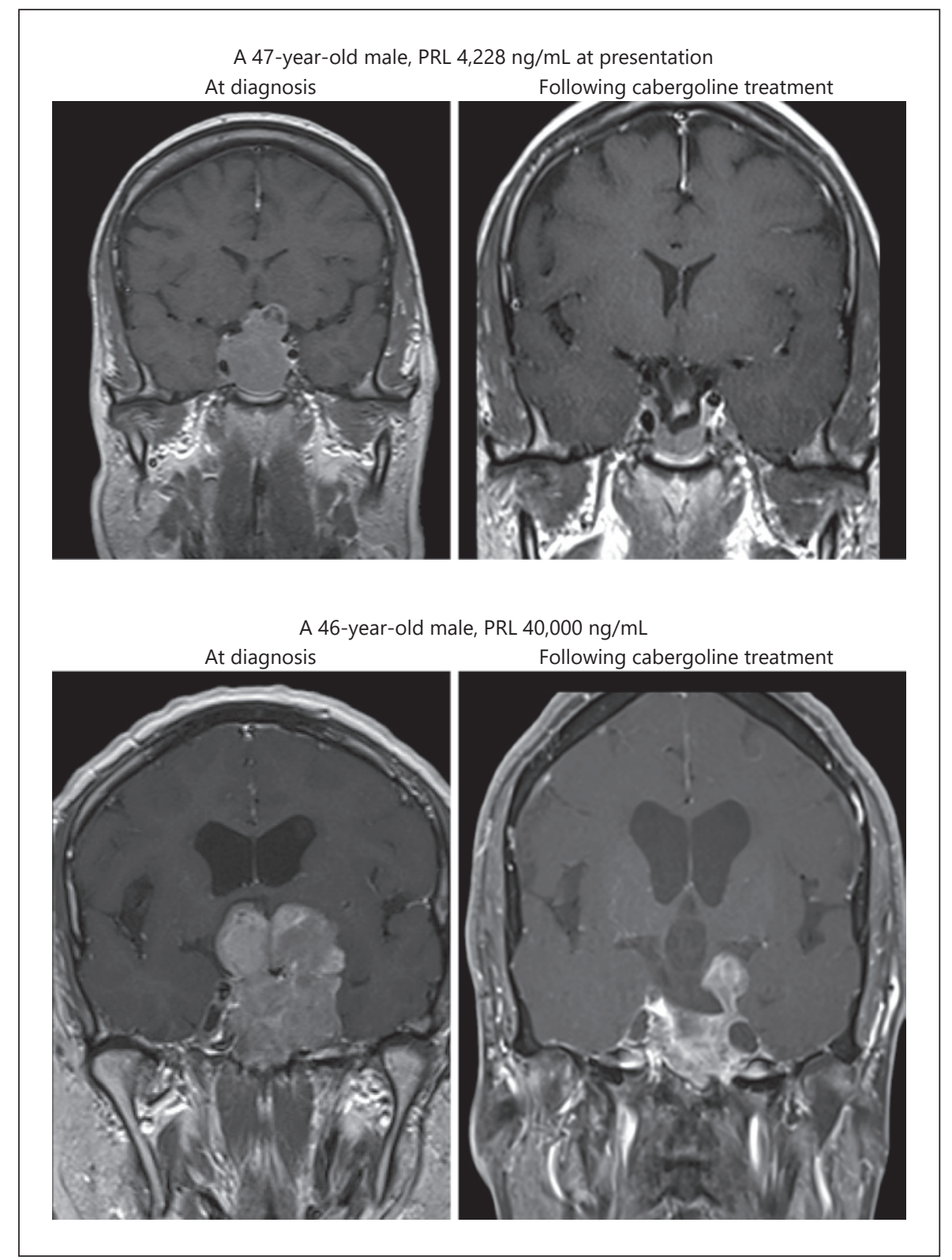

clivus and, rarely, posteriorly into the brainstem. Although the imaging (CT and MRI) appearance of these tumors, especially those larger than $60 \mathrm{~mm}$, suggests a malignant neoplasm not necessarily of pituitary origin, giant prolactinomas are benign and treatable, with similar histological and clinical characteristics to the smaller macroprolactinomas. Only rarely do they carry predictive markers for malignant potential or develop into malignant prolactin-secreting carcinomas. In pituitary tumors, the only suggested proliferation marker of invasiveness and possible malignancy to date is a high Ki-67 labelling index (>10\%). Besides prolactin, a minority of giant prolactinomas express and also secrete growth hormone [7]; co-secretion of other pituitary hormones, mainly thyroid-stimulating hormone, has been reported as well.

Treatment goals for giant prolactinomas are the same as for the more common and smaller macroprolactinomas, including normalization or at least substantial suppression of prolactin level, tumor shrinkage with relief of compression of adjacent structures, particularly the optic chiasm (causing visual field damage) and cranial nerves (causing ophthalmoplegia), increase/normalization of 
Table 1. Response to medical treatment with dopamine agonists based on prolactinoma size

\begin{tabular}{|c|c|c|c|c|c|c|}
\hline Adenoma size & Gender & $\begin{array}{l}\text { Visual } \\
\text { damage }\end{array}$ & Surgery & $\begin{array}{l}\text { PRL } \\
\text { normalized }\end{array}$ & $\begin{array}{l}\text { Testosterone } \\
\text { normalized }\end{array}$ & Ref. \\
\hline Microadenomas & $\mathrm{F}>\mathrm{M}$ & None & Rare & $80-95 \%$ & $90 \%$ & {$[3]$} \\
\hline Giant prolactinomas $>40 \mathrm{~mm}$ & $M: F-9: 1$ & $70 \%$ & $15 \%$ & $60-68 \%$ & $40-67 \%$ & {$[4,5,21]$} \\
\hline Giant prolactinomas $>60 \mathrm{~mm}$ & $\mathrm{M}: \mathrm{F}-9: 1$ & $80 \%$ & $50 \%$ & $61 \%$ & $37 \%$ & [7] \\
\hline
\end{tabular}

testosterone level (to achieve eugonadism and improve reproductive potential), and recovery of altered pituitary axes [8]. However, if the tumor is particularly large and there is long-standing damage to the visual tracts or pituitary hormone function, visual recovery or restoration of gonadal function may not be realistic.

\section{Clinical Symptoms}

Men may complain of hypogonadism, erectile dysfunction, visual problems, weakness, and headaches. Galactorrhea is rare. Symptoms in men are typically missed for a long time, sometimes even years, before a diagnosis is made. Women may present with primary or secondary amenorrhea, headaches, and visual deterioration, and in the younger age group, galactorrhea. Long-standing hypopituitarism is reported occasionally. Patients, especially elderly, may be diagnosed incidentally by CT or MRI performed for unrelated reasons. When the giant prolactinoma extends into surrounding cerebral structures, the resulting neurologic and cognitive deterioration may lead to such atypical symptoms as frontal behavioral changes $[9,10]$, disorientation, reversible dementia [11], hemiparesis, olfactory hallucinations, and temporal epilepsy [12]. Other symptoms that may accompany giant prolactinomas include CSF rhinorrhea, nasal congestion and epistaxis, exophthalmus [13], and cranial nerve palsies (III, IV, V, VI) with ophthalmoplegia and obstructive hydrocephalus [14]. Intensive treatment can be efficacious and reverse these symptoms.

\section{Medical Treatment}

Giant prolactinomas have been reported and characterized in the literature in small series by several groups, including ours $[5,15-18]$. In the past, the primary treatment was pituitary surgery for immediate relief of the vi- sual and neurologic symptoms [19]. However, surgery has since been replaced by medical treatment with dopamine agonists, originally bromocriptine and currently cabergoline, as the first-line option. Treatment with dopamine agonists has been found to lead to rapid and striking tumor shrinkage, with possible significant visual improvement within a short period of time, even in patients with complicated giant prolactinomas.

In general, medically treated prolactinomas have a high remission rate of $90 \%$ [3]. When they are large and extend outside the sellar borders, the rate of prolactin normalization decreases to $70-80 \%$ for macroprolactinomas [3] and 60-68\% for giant prolactinomas [4, 5] (Table $1)$. This remission rate is not surprising as the mitotic rate and proliferation index of the giant invasive tumors is only mildly increased relative to the smaller macroprolactinomas [20]. Maiter and Delgrange [5] summarized 13 series including a total of 97 patients with giant prolactinomas primarily treated with bromocriptine or cabergoline. Prolactin normalized in 58 patients $(60 \%)$ and was significantly suppressed in most of the remainder. After a mean follow-up of 37 months, considerable tumor shrinkage $(30 \%$ reduction in tumor diameter or $65 \%$ decrease in adenoma volume) was observed in $74 \%$ of patients, and visual improvement was observed in $96 \%$ of the patients who presented with visual field defects. Half of all male patients with giant prolactinomas have persistent hypogonadism while on dopamine agonists. In a large series from Mexico of 42 men with giant prolactinomas [21], cabergoline treatment (median dose, $2 \mathrm{mg} /$ week) resulted in prolactin normalization in $68 \%$ and reduction of $>50 \%$ of tumor volume in $87 \%$. Recovery of hypogonadism and visual improvement occurred in 32 and $68 \%$, respectively. Only 6 men required surgery. In another cohort of 18 patients with particularly large giant macroprolactinomas measuring $>60 \mathrm{~mm}$ in diameter [7], which are typically characterized by aggressive behavior and invasiveness with massive extrasellar extension, the authors reported a similar remission rate to the Mexican 
study (61\%) using a high dose of cabergoline (median dose, $3.5 \mathrm{mg} /$ week) for a median of 20 months. However, testosterone normalized in only 6 of the 16 male patients [7] and 9 patients (50\%) required surgery (Table 1). Only $10 \%$ of all giant prolactinomas occur in women [6] at a median age of 44 years at diagnosis. One study of 34 women with giant prolactinomas showed that cabergoline treatment effectively normalized prolactin levels in 55\% [6].

Cabergoline is the preferred dopamine agonist over bromocriptine for the treatment of giant prolactinomas because it has a better effect on prolactin levels, albeit with no advantage in terms of tumor shrinkage [22]. In patients with bromocriptine-resistant giant prolactinomas, prolactin levels may normalize when treatment is switched to cabergoline [23]. The treatment protocol with cabergoline consists of the same starting dose as for macroprolactinomas $(0.5-1.0 \mathrm{mg} / \mathrm{week})$, which is then individually adjusted according to the prolactin response. Rapid dose escalation may lead to massive tumor shrinkage with a potential risk of apoplexy or CSF leak [24, 25]. Lifetime continuous dopamine agonist treatment is required in almost all patients to maintain prolactin suppression and prevent tumor regrowth. Withdrawal of treatment poses a risk of rapid tumor re-expansion, but a dose decrease is possible if long-lasting normoprolactinemia is preserved and the tumor mass is controlled.

\section{Pituitary Surgery}

Transsphenoidal or transcranial resection may be offered to the subset of patients with giant prolactinoma for whom even high-dose medical therapy fails to achieve tumor and hormonal control [26], and patients with apoplexy or complications of pharmacological treatment (CSF leak). The reported rate of surgery following firstline dopamine agonist treatment is $13-14 \%$ [5]. Severe chiasmal compression might also lead to a decision to operate, although even severe optic damage and significant visual field defects can improve with medical treatment alone $[4,5]$.

However, surgery is rarely curative. Most patients will not achieve hormonal remission postoperatively $[3,5]$, will remain with a significant adenoma residue, and will require continuous medical treatment. Surgical resection may also be hampered by intratumoral fibrosis, which may develop following long-term dopamine agonist management [27, 28]. Moreover, surgery in patients with gigantic tumors can be associated with complications such as diabetes insipidus, mental deterioration, CSF leak, meningitis, worsening vision, and even perioperative mortality [19].

\section{Radiotherapy}

Radiotherapy may serve as adjuvant therapy in patients with giant prolactinoma resistant to dopamine agonists, preferentially after debulking surgery. To increase the chance of success, discontinuation of dopamine agonist treatment before and during radiotherapy is frequently recommended. It is difficult to distinguish the effects of radiotherapy from the effects of concurrent medical treatment or previous surgery. In a series of 20 patients with invasive giant prolactinomas treated with bromocriptine, 11 underwent also adjuvant radiotherapy. The authors concluded that traditional radiotherapy did not enhance the effect of bromocriptine on tumor shrinkage compared to patients who did not receive radiotherapy [29]. Irradiated patients should be followed regularly for the possible development of pituitary hormone dysfunction.

\section{Other Treatment Options}

\section{Temozolomide}

Temozolomide (TMZ) is an oral alkylating agent used in the treatment of malignant brain tumors. It was introduced in 2006 for the treatment of aggressive pituitary adenomas and carcinomas, with good results [30, 31], and in the last decade, studies have found it to be a useful option for certain aggressive and resistant giant and malignant prolactinomas. TMZ is generally well tolerated, but some patients experience nausea, fatigue, leukopenia, and thrombopenia. A recent systematic review of the literature [32] yielded 23 cases of prolactinsecreting adenomas and 19 of prolactin-secreting carcinomas treated with TMZ. The tumor decreased to varying extents in $76 \%$ of patients, with a significant reduction of prolactin level in $75 \%$, including a few patients with prolactin normalization. However, researchers tend to report rare tumors with a good response to novel therapies rather than resistant ones, leading to a possible publication bias. Some studies of aggressive pituitary adenomas reported a strong association between negative staining for the DNA repair protein $\mathrm{O}^{6}$-methylguanineDNA methyltransferase (MGMT) and good response to TMZ [33]. 
Testosterone Replacement

Persistent hypogonadism is very common in patients treated with dopamine agonists, even after normoprolactinemia is achieved. This finding is attributed to the longstanding mass effect of the giant tumor, with continuous destruction of the normal pituitary gonadotrophic cells, precluding gonadotropin stimulation of testosterone. Apart from sexual dysfunction and suppressed libido, hypogonadism in men may be associated with reversible anemia [34] and osteoporosis. In these cases, testosterone replacement is usually beneficial. There is a potential risk of tumor enlargement due to testosterone aromatization to estradiol, with a possible direct effect of estradiol on lactotroph cell hyperplasia, but it occurs only rarely [35].

\section{Treatment Complications}

Besides CSF leak/rhinorrhea discussed above [25], long-term use of dopamine agonists may be associated with several other rare complications. Fibrosis of cardiac valves leading to cardiac valvulopathy was demonstrated in patients with Parkinson's disease treated with high doses of dopamine agonists. However, at the doses typically used for prolactinomas, cabergoline appears to be safe, with no evidence of a clinically relevant effect on cardiac valve function [36]. Impulse control disorders have been reported in patients receiving dopamine agonists for prolactinoma, including disruptive hypersexuality ("Dopatestotoxicosis") [37], financial loss, and reduced work performance. Usually, these phenomena were reversed on dose decrease or discontinuation of the drug.

\section{Conclusion}

Giant prolactinomas are generally benign but they may be aggressive and invasive, disrupting nearby structures and increasing prolactin levels. They show a fairly good response to medical treatment with dopamine agonists, combined with surgery in some patients and radiotherapy if required. This multimodal approach may effectively suppress prolactin levels to normal or close to normal in most cases, often accompanied by dramatic tumor shrinkage. The clinical response rate is almost similar to that reported for smaller medically treated macroprolactinomas.

\section{Statement of Ethics}

The author has no ethical conflicts of interest to disclose.

\section{Disclosure Statement}

The author has no conflicts of interest to declare.

\section{Funding Sources}

No funding was procured for this work.

\section{References}

1 Fernandez A, Karavitaki N, Wass JA. Prevalence of pituitary adenomas: a communitybased, cross-sectional study in Banbury (Oxfordshire, UK). Clin Endocrinol (Oxf). 2010 Mar;72(3):377-82.

2 Colao A, Sarno AD, Cappabianca P, Briganti F, Pivonello R, Somma CD, et al. Gender differences in the prevalence, clinical features and response to cabergoline in hyperprolactinemia. Eur J Endocrinol. 2003 Mar;148(3): 325-31.

3 Gillam MP, Molitch ME, Lombardi G, Colao A. Advances in the treatment of prolactinomas. Endocr Rev. 2006 Aug;27(5):485-534.

4 Moraes AB, Silva CM, Vieira Neto L, Gadelha MR. Giant prolactinomas: the therapeutic approach. Clin Endocrinol (Oxf). 2013 Oct; 79(4):447-56.
5 Maiter D, Delgrange E. Therapy of endocrine disease: the challenges in managing giant prolactinomas. Eur J Endocrinol. 2014 Jun; 170(6):R213-27.

6 Delgrange E, Raverot G, Bex M, Burman P, Decoudier B, Devuyst F, et al. Giant prolactinomas in women. Eur J Endocrinol. 2013 Nov;170(1):31-8.

7 Shimon I, Sosa E, Mendoza V, Greenman Y, Tirosh A, Espinosa E, et al. Giant prolactinomas larger than $60 \mathrm{~mm}$ in size: a cohort of massive and aggressive prolactin-secreting pituitary adenomas. Pituitary. 2016 Aug;19(4):429-36.

8 Melmed S, Casanueva FF, Hoffman AR, Kleinberg DL, Montori VM, Schlechte JA, et al.; Endocrine Society. Diagnosis and treatment of hyperprolactinemia: an Endocrine Society clinical practice guideline. J Clin Endocrinol Metab. 2011 Feb;96(2):273-88.
9 Arshad MF, Arambewela M, Debono M. Atypical giant prolactinoma with frontal lobe manifestations. BMJ Case Rep. 2018 Sep; 2018:bcr-2018-226982

10 Grozinsky-Glasberg S, Shimon I. Unusual clinical presentations of giant prolactinomas. Pituitary. 2011 Dec;14(4):340-4.

11 Brisman MH, Fetell MR, Post KD. Reversible dementia due to macroprolactinoma. Case report. J Neurosurg. 1993 Jul;79(1):135-7.

12 Deepak D, Daousi C, Javadpour M, MacFarlane IA. Macroprolactinomas and epilepsy. Clin Endocrinol (Oxf). 2007 Apr;66(4):5037.

13 Siddiqui A, Chew N, Miszkiel K. Case report unusual orbital invasion by a giant prolactinoma. Br J Radiol. 2008 Nov;81(971):e25962. 
14 Alkatari S, Aljohani N. Obstructive hydrocephalus, fifth nerve and hypothalamus involvement: acute presentation of a giant prolactinoma. Clin Med Insights Case Rep. 2012; 5:115-8.

15 Shrivastava RK, Arginteanu MS, King WA, Post KD. Giant prolactinomas: clinical management and long-term follow up. J Neurosurg. 2002 Aug;97(2):299-306.

16 Corsello SM, Ubertini G, Altomare M, Lovicu RM, Migneco MG, Rota CA, et al. Giant prolactinomas in men: efficacy of cabergoline treatment. Clin Endocrinol (Oxf). 2003 May; 58(5):662-70.

17 Shimon I, Benbassat C, Hadani M. Effectiveness of long-term cabergoline treatment for giant prolactinoma: study of 12 men. Eur J Endocrinol. $2007 \mathrm{Feb}$;156(2):225-31.

18 Acharya SV, Gopal RA, Menon PS, Bandgar TR, Shah NS. Giant prolactinoma and effectiveness of medical management. Endocr Pract. 2010 Jan-Feb;16(1):42-6.

19 Garibi J, Pomposo I, Villar G, Gaztambide S. Giant pituitary adenomas: clinical characteristics and surgical results. Br J Neurosurg. 2002 Apr;16(2):133-9.

20 Madsen H, Borges TM, Knox AJ, Michaelis KA, Xu M, Lillehei KO, et al. Giant pituitary adenomas: pathologic-radiographic correlations and lack of role for p53 and MIB-1 labeling. Am J Surg Pathol. 2011 Aug;35(8):1204-13.

21 Espinosa E, Sosa E, Mendoza V, Ramírez C, Melgar V, Mercado M. Giant prolactinomas: are they really different from ordinary macroprolactinomas? Endocrine. 2016 Jun;52(3): 652-9.

22 Huang HY, Lin SJ, Zhao WG, Wu ZB. Cabergoline versus bromocriptine for the treatment of giant prolactinomas: A quantitative and systematic review. Metab Brain Dis. 2018 Jun; 33(3):969-76.
23 Huang HY, Zhai W, Tang H, Hui GZ, Wu ZB. Cabergoline for the treatment of bromocriptine-resistant invasive giant prolactinomas. Endocrine. 2018 Nov;62(2):464-9.

24 Chng E, Dalan R. Pituitary apoplexy associated with cabergoline therapy. J Clin Neurosci. 2013 Dec;20(12):1637-43.

25 Česák T, Poczos P, Adamkov J, Náhlovský J, Kašparová $\mathrm{P}$, Gabalec F, et al. Medically induced CSF rhinorrhea following treatment of macroprolactinoma: case series and literature review. Pituitary. 2018 Dec;21(6):561-70.

26 Andujar-Plata P, Villar-Taibo R, BallesterosPomar MD, Vidal-Casariego A, Pérez-Corral B, Cabezas-Agrícola JM, et al. Long-term outcome of multimodal therapy for giant prolactinomas. Endocrine. 2017 Jan;55(1):231-8.

27 Bevan JS, Adams CB, Burke CW, Morton KE, Molyneux AJ, Moore RA, et al. Factors in the outcome of transsphenoidal surgery for prolactinoma and non-functioning pituitary tumour, including pre-operative bromocriptine therapy. Clin Endocrinol (Oxf). 1987 May; 26(5):541-56.

28 Mohan N, Chia YY, Goh GH, Ting E, Teo K, Yeo TT. Cabergoline-induced fibrosis of prolactinomas: a neurosurgical perspective. BMJ Case Rep. 2017 Nov;2017:bcr-2017-220971.

$29 \mathrm{Wu} \mathrm{ZB}$, Yu CJ, Su ZP, Zhuge QC, Wu JS, Zheng WM. Bromocriptine treatment of invasive giant prolactinomas involving the cavernous sinus: results of a long-term follow up. J Neurosurg. 2006 Jan;104(1):54-61.

$30 \operatorname{Lim}$ S, Shahinian H, Maya MM, Yong W, Heaney AP. Temozolomide: a novel treatment for pituitary carcinoma. Lancet Oncol. 2006 Jun;7(6):518-20.
31 Syro LV, Uribe H, Penagos LC, Ortiz LD, Fadul CE, Horvath E, et al. Antitumour effects of temozolomide in a man with a large, invasive prolactin-producing pituitary neoplasm. Clin Endocrinol (Oxf). 2006 Oct;65(4):552-3.

32 Almalki MH, Aljoaib NN, Alotaibi MJ, Aldabas BS, Wahedi TS, Ahmad MM, et al. Temozolomide therapy for resistant prolactin-secreting pituitary adenomas and carcinomas: a systematic review. Hormones (Athens). 2017 Apr;16(2):139-49.

33 Bengtsson D, Schrøder HD, Berinder K, Maiter D, Hoybye C, Ragnarsson O, et al. Tumoral MGMT content predicts survival in patients with aggressive pituitary tumors and pituitary carcinomas given treatment with temozolomide. Endocrine. 2018 Dec;62(3): 737-9.

34 Shimon I, Benbassat C, Tzvetov G, Grozinsky-Glasberg S. Anemia in a cohort of men with macroprolactinomas: increase in hemoglobin levels follows prolactin suppression. Pituitary. 2011 Mar;14(1):11-5.

35 Prior JC, Cox TA, Fairholm D, Kostashuk E, Nugent R. Testosterone-related exacerbation of a prolactin-producing macroadenoma: possible role for estrogen. J Clin Endocrinol Metab. 1987 Feb;64(2):391-4.

36 Vroonen L, Lancellotti P, Garcia MT, Dulgheru R, Rubio-Almanza M, Maiga I, et al. Prospective, long-term study of the effect of cabergoline on valvular status in patients with prolactinoma and idiopathic hyperprolactinemia. Endocrine. 2017 Jan;55(1):239-45.

37 De Sousa SM, Chapman IM, Falhammar H, Torpy DJ. Dopa-testotoxicosis: disruptive hypersexuality in hypogonadal men with prolactinomas treated with dopamine agonists. Endocrine. 2017 Feb;55(2):618-24. 